\title{
In This Issue. . .
}

Just when you thought that you were becoming comfortable with the post-post world - a world no longer with a single cold war but more hot ones, and a world where ideological suspicion was replaced by intra-state animosities - International Politics again offers a series of unsettling questions and provocative arguments. Indeed, Volume 38, Number 3 contains more than enough to shake some academic and policy trees.

Read further, and you'll see scholars based in the US, Egypt, Israel and Denmark using methodologies ranging from critical theory to Probit, examining discourse qualitatively or trade data through a multivariate quantitative model-tackling some of the most persistent and essential questions of the field. As appropriate for a journal of transnational issues and global problems, each of our five principal articles has a long reach and strong grasp on enduring issues.

At the forefront of academic inquiry and policy debates today are, unquestionably, how states are challenged by autonomy or independence movements and how demographic labels such as "others" and "foreigners" allow those in power to raise the specter of threat against which any measure is justifiable. Our first two articles examine both elements-as movements seek external support against the state, and as those in power reach for tools against anyone or anything "different."

Clifford Bob (Duquesne University) takes us to Nigeria and Mexico to examine the Ogoni and Zapatista cases - indigenous movements of rebellion or resistance seeking external NGO support during the 1990s. Bob asks how (and why) the Zapatistas and Ogoni movements both managed to gain substantial visibility and credibility, eliciting significant international NGO largesse and political support, conversely, he asks why other contemporary groups in both countries failed to gain such NGO backing and never obtained a global media foothold. By raising such a question, Bob probes the nature of "global civil society" and forces us to reconsider assumptions that such a stratum of political activity is benign, based on higher principles or outside market competitiveness. Indeed, we learn that developing a message and having the right messenger (and it doesn't hurt if s/he happens to have some source of independent wealth) are essential features in a movement's capacity to establish bonds with funding agencies and the international NGO advocacy community. It isn't by accident, in other words, that the Ogoni and Zapatistas managed so well, and developed friendships with human rights, "native peoples" and other NGOs based in London, New York, Washington, DC, etc. Their leaders, strategies, timing and other factors raised their potential far above others. But, Bob's key finding is that the milieu of "rebellion" today is one of marketing a group and leaders to a primarily Western clientele to whom innumerable appeals are made and whose sympathy is highly fickle. Clifford Bob's analysis is a welcome corrective, lest we think that high moral principles determine which movements receive whose support. 
Those in power-elected or otherwise-don't take this lying down. They fight back. Today, their arsenal includes not only or primarily arrests during the night or surveillance during the day. States' self-defense can, and does include a sophisticated effort to define, portray and denote any critics of the regime, and anyone who advocates greater autonomy from the center, as "others," "foreigners," and/or an externally-manipulated threat.

Critical demography is Mark Salter's (American University of Cairo) answer. In a wide-ranging essay, Salter examines how demographic discourse insists on pejorative identities for immigrants, refugees and foreigners, damaging to all aspects of national security. By characterizing a group or community as "other" in demographic rhetoric, international relations literature contributes to the domestic and external political needs of those in power. And, thus, Salter tries to exorcise from demographic discourse the visceral fear of a changing or unstable national community-looking for ways to question "natural" boundaries of communities and rejecting the reification of fear directed (often) against the same kinds of groups that Clifford Bob considers in his essay.

There is no escape (nor should there be) from the big questions of international politics in our next three articles in Volume 38, Number 3. In the first of these, Hans Henrik Holm (Danish School of Journalism, Aarhus) explores the early postCold War efforts to form a universal policy on how to manage state failure to a "policy" of ad hoc case-specific response to state failure. This recourse to regional, ad hoc response results in a disaggregated world order. In this disaggregated world order, some state failures prompt outside intervention while others are left to collapse in humanitarian disasters.

Perhaps no literature within international relations or world politics has expanded and taken root more than "democratic peace" (DP). Hemda Ben-Yehuda and Iris Margulies (both from Bar Ilan University in Israel) open an entirely new path of research within that literature-taking issue with the notion that regime type (being democratic vis-à-vis authoritarian) has direct affect on war-proneness. They argue - provocatively, but convincingly - that there is more to this relationship. Of particular importance to Ben-Yehuda and Margulies is the role of stress (what others might call "threat"). If the crisis-initiator senses no reciprocal threat, it is an "opportunity crisis;" if reciprocal or mutual stress (threat) exists, it is a "threat crisis." In the former, their findings suggest, democracies and non-democracies behave similarly; only when democracies confront reciprocal threat in a crisis do their "democratic traits" make a behavioral difference. These are important, preliminary findings; for, if democracies really don't differ much from non-democracies absent a visceral threat to democracies, it says a lot about the inherent flaws of the democratic peace literature. While many have weighed in on the benefits and flaws of democratic peace studies, fundamental assumptions are rarely challenged. From Ben-Yehuda and Margulies, we learn clearly that the DP findings (the "democracies don't fight democracies" mantra) are incomplete and misleading-and that there is a lot more work to do.

And, like the DP literature, assumptions abound regarding the elixir of trade. If you "do business" together, how could you fight? If two countries engage in the 
intimacy of trade, how could they resort to arms against each other in a dispute? A la Thomas Friedman, countries with many McDonalds outlets are unlikely to fight each other. But, like Ben-Yehuda and Margulies, Rafael Reuveny (Indiana University, Bloomington) find the relationship between trade and conflict much more complex. More imports and exports do not, alone, make for friendships. Indeed, only certain types of goods (not total trade levels) seem sensitive to the proclivity for conflict (e.g., energy). Buying a lot from, and selling a lot to China - remaining "engaged" in other words - has not nor will it ensure non-conflict with Beijing.

For both Reuveny and Ben-Yehuda and Margulies, core questions concern how the 21 st century can identify sources of conflict and protect against them. Do regime type (democracy) and aggregate trade levels reduce the propensity for conflict? Their answers suggest, strongly, that avoiding war and conflict are far, far more complex issues than just trying to enlarge the number of democracies or spreading the global benefits of free trade.

Tracking principal directions in the literature, our Book Review section features two essays sure to be useful to our readers. Stephen Hartlaub (Frostburg State University) provides an important assessment of teaching tools in our field - without which the complex issues considered in the foregoing articles cannot be transferred effectively in the classroom. John Quinn (Truman State University) focuses on several recent works about state failure in Africa and is, thereby, linked to the Holm article introduced above.

Marketing rebellion, denoting identities, disaggregating state systems, redefining democratic peace, and refining the link between trade and conflict - these are tall orders for one issue of one volume of one journal. Such fundamental withinand-between-states processes and fault lines, even as those distinctions fade or are redrawn, are the stuff of world affairs in the early 21 st century.

No doubt, by publishing these studies, International Politics enlarges the debate rather than resolves issues. That is as it should be. After all, we expect that topics of such scope will be recurring features of academic debate and policy-making in future decades, providing ample material for many issues in years to come. 